Генеральный директор РГП «Госградкадастр», доктор технических наук, профессор ЕНУ им. Л.Н. Гумилева, академик НИА РК, Почетный строитель, Почетный архитектор и

Заслуженный работник науки Казахстана, г. Астана, Казахстан

E-mail: ospan_ailina@inbox.ru ORCID ID 0000-0003-4960-6727

Ильясов Серик Сапаргалиевич, Жамбайбеков Даулет Каленович

Главный специалист Отдела расселения и развития производительных сил

Управления территориального планирования РГП «Госградкадастр»

г. Астана, Казахстан

\title{
ПЕРСПЕКТИВЫ РАЗВИТИЯ ПРОМЫШЛЕННОСТИ ШЫМКЕНТСКОЙ АГЛОМЕРАЦИИ
}

\begin{abstract}
Аннотация: В статье проведен анализ экономического потенциала Шымкентской агломерации, на основании которого выявлены основные направления развития региона. С учетом имеющегося потенциала текущчих и перспективных социально-экономических условий определены приоритетные направления формирования экономики кластерного типа в сфере фармацевтики, нефтепереработки, производства строительных материалов, легкой промышленности, производства продуктов питания и металлургии. Наряду с этим, отражены тенденции развития инвестиционных зон как перспективных точек роста Шымкентской агломерации.
\end{abstract}

Ключевые слова: Шымкентская агломерачия, развитие региона, тип кластера, легкая промышленность, инвестиционные зоны.

Mussabayev Turlybek Turkpenovich

General Director of the Republic State Enterprise «Republic center of State Urban Planning and Cadastre», Doctor of technique sciences, Professor of the L.N. Gumilev Eurasian National University, Academician of the National Academy of Engineering of the Republic of Kazakhstan, the Honorable Builder, the Honoured Worker of Science of the Republic of Kazakhstan. Astana city, Kazakhstan E-mail: ospan_ailina@inbox.ru ORCID ID 0000-0003-4960-6727 Ilyasov Serik Sapargalievich \& Zhambaybekov Daulet Kalenovich Chief Specialist of the Department of Settlement and Development of Productive Forces Office of Territorial Planning RSE "Gosgradkadastr"

Astana, Kazakhstan

\section{PROSPECTS OF DEVELOPMENT OF THE INDUSTRY OF SHYMKENT AGGLOMERATION}

Annotation: The analysis of economic potential of Shymkent of agglomeration is conducted in the article, on the basis of that basic directions of development of region are educed. Taking into account present potential of current and perspective socio-economic terms priority directions of forming of economy of cluster type are certain in the field of pharmaceutics, oil processing, production of building materials, light industry, production of foodstuffs and metallurgy. Side by side with this, progress of investment zones trends are reflected as prospects.

Key words: Shymkent agglomeration, regional development, cluster type, light industry, investment zones.

Промышленность является основным локомотивом экономики любой страны и одним из основных факторов формирования большинства территориальных социальноэкономических систем, в частности, агломераций. В настоящее время, несмотря на

Перспективы развития промышленности агломерации
Материалы Международной практической интернет-конференции «Актуальные Проблемы Науки» 
мировую тенденцию развития сферы услуг, значительная часть основных фондов и трудовых ресурсов сконцентрирована в промышленности.

Городское расселение тесно взаимосвязано с промышленной специализацией хозяйства регионов. Развитие промышленности влечет за собой рост поступлений в государственный бюджет, увеличение обеспеченности соответствующего уровня предложения на ряд товаров личного потребления, снижение уровня безработицы. Таким образом, территориальная организация населения и промышленное производство имеет большую зависимость между собой и определяет уровень устойчивого развития региона.

Важность промышленности для устойчивого развития отражено в Послании Президента Республики Казахстан Н. Назарбаева народу Казахстана от 10 января 2018 года «Новые возможности развития в условиях четвертой промышленной революции», согласно которому промышленность должна стать «флагманом преобразований» при внедрении технологии уклада 4.0. Внедрение технологии уклада 4.0 предусматривается в рамках реализации Послания Президента Республики Казахстан народу Казахстана от 14 декабря 2012 года «Стратегия «Казахстан - 2050»: новый политический курс состоявшегося государства», основные направления которого отражены в Межрегиональной схеме территориального развития Шымкентской агломерации (далее - Межрегиональная схема), разработанной на основании постановления Правительства Республики Казахстан от 30 декабря 2013 года № 1434 «Об утверждении Основных положений Генеральной схемы организации территории Республики Казахстан» и Указа Президента Республики Казахстан от 1 августа 2014 года № 874 «Об утверждении Государственной программы индустриально-инновационного развития Республики Казахстан на 2015 - 2019 годы» $[1,2,3]$.

Согласно Межрегиональной схеме в зону влияния Шымкентской агломерации входят: город Шымкент (ядро агломерации), Байдибекский, Казыгуртский, Ордабасынский, Сайрамский, Сарыагашский, Толебийский, Тюлькубасский районы, а также территория Арысской городской администрации.

В роли контрмагнитов определены административные центры районов - города Сарыагаш, Арысь, село им. Т. Рыскулова, а также города-спутники/центры внутренней миграции населения (г. Ленгер, села Аксу, Казыгурт, Бадам, Темирлановка, Тортколь, Чаян) [1].

Согласно предварительным данным за 2017 год объем промышленного производства районов и городов, вошедших в территорию Шымкентской агломерации, составил 561,1 млрд. тенге или 65,4\% от общеобластного показателя [4].

Основными предпосылками развития Шымкентской агломерации является месторасположение с возможностью сотрудничества с Китаем, Узбекистаном и Кыргызстаном, наличие благоприятных климатических условий для развития сельского хозяйства, наличие богатой минерально-сырьевой базы, развитая обрабатывающая промышленность и транспорт.

Одним из основных факторов, который окажет влияние на развитие Шымкентской агломерации, должно стать ее расположение на «Новом Шелковом пути» между Китаем и Европой, а также наличием железной дороги Казахстан - Туркменистан - Иран.

В среднесрочной перспективе планируется строительство транспортнологистического центра в городе Шымкент для эффективной поддержки сельхозтоваропроизводителей региона, обеспечения выхода продукции отечественных производителей на внешние и внутренние рынки и обслуживания транзитных грузопотоков между Европой и Китаем, Средней и Юго-Восточной Азией. Подобные центры будут функционировать в городе Арысь, Сарыагашском и Тюлькубасском районах.

Перспективы развития промышленности агломерации
Материалы Международной практической интернет-конференции «Актуальные Проблемы Науки» 
Перспективной специализацией Шымкентской агломерации станет производство продуктов питания, производство нефти и нефтепродуктов, текстильной продукции, строительных материалов, металлургии, машиностроение, химическая промышленность.

Пищевая промышленность будет развиваться за счет использования местного сырья, увеличения объемов инвестиций в отрасль и создания новых конкурентоспособных производств, что в итоге должно привести к снижению импортозависимости.

Необходимо создание продовольственного пояса вокруг города Шымкент путем создания современных откормочных и молочных комплексов, строительства тепличных комплексов, плодо- и овощехранилищ, закладки фруктовых садов и виноградников в периферийных зонах и развитие сети перерабатывающих предприятий.

Одним из перспективных направлений промышленности является металлургия. Увеличение объема добычи металлов позволит производить широкий ассортимент сплавов для последующего применения в различных отраслях экономики, таких как машиностроение, строительная индустрия, электроника и электроприборы, производство труб и кабелей и др.

Основной металлургической продукцией агломерации станут изделия из черных и цветных металлов, сварочные электроды, металлоконструкции, электросварные трубы, шовные трубы, трансформаторные подстанции и др.

Продукция металлургической промышленности будет производиться в основном в городе Шымкент и Сайрамском районе.

Перспективным направлением развития Шымкентской агломерации останется производство продуктов нефтепереработки.
Основными
предприятиями
данной
отрасли
являются:

ТОО «ПетроКазахстан Ойл Продактс» (бензин, керосин авиационный, дизельное топливо, мазут топочный), TOO «HILL Corporation» (моторные масла, трансмиссионные масла и смазочные материалы), ТОО «Газпромнефть-Битум Казахстан» (битум).

Дальнейшее развитие отрасли будет связано с увеличением объемов и глубины переработки нефти, расширением ассортимента выпускаемой продукции.

Ввод в действие комплекса глубокой переработки нефти позволит Шымкентскому нефтеперерабатывающему заводу выйти на качественно новый уровень технологического развития, что обеспечит более квалифицированную переработку нефтяного сырья, выработку экологически чистых моторных топлив, а также усилит роль предприятия как экспортера товарной продукции в страны ближнего и дальнего зарубежья.

Одним из перспективных направлений развития агломерации станет текстильная промышленность, производство кожаной и относящейся к ней продукции. Основными предприятиями легкой промышленности являются АО «Қазақстан Мақтасы», АО «Меланж», TOO «SOUTH TEXTILINE KZ», АО «Ютекс», TOO «Фирма «Восход», ТОО «Эластик LTD», TOO «Швейная фабрика «Гаухар», TOО «Швейная фабрика «Сауле». производителями текстильных изделий

будут TOO «SOUTH TEXTILINE KZ» (производство хлопчатобумажной пряжи и суровых хлопчатобумажных тканей), АО «Меланж» (производство хлопчатобумажной пряжи), АО «Ютекс» (производство пряжи, выпуск элитных швейных изделий).

В перспективе большое внимание будет уделяться производству кожаных изделий. Основными предприятиями по производству кожаных изделий станут - TOO «Turan-Skin» (хромовый полуфабрикат: дубленная кожа из шкур КРС и MPC), TOO «LEON» (переработка шкур МРС, КРС).

Перспективы развития промышленности агломерации
Материалы Международной практической интернет-конференции «Актуальные Проблемы Науки» 
Развитие отрасли строительных материалов будет связано с производством цемента, кирпича, извести гашенной, негашенной, шифера и асботруб, изделий из бетона для строительных целей, бетона товарного и др.

Увеличение объемов производства строительных материалов предполагается за счет завершения разведки месторождений кирпичного сырья, песка, известняка, глины, кварцевого песка, строительного камня и других полезных ископаемых в Байдибекском, Казыгуртском, Ордабасынском, Сарыгашском, Толебийском районах.

Развитие машиностроительной отрасли будет связано с модернизацией крупных и средних предприятий, которые будут производить строительно-дорожную технику, трансформаторы, тракторы и др.

Основные предприятия агломерации ТОО «Шымкентремсервис», АО «Шымкентский механический завод», Шымкентский завод ЭМИ филиала АО «ЭЛМО», ТОО «Коныр ат», АО «ЮКМЗ», ТОО «КазКиоти», ТОО «Ленгерский машиностроительный завод».

Перспектива развития фармацевтической и химической промышленности связана с производством фармацевтических препаратов, фосфора и его соединений.

В фармацевтической промышленности перспективной продукцией будут лекарственные препараты, субстанции, ампулы, порошковые антибиотики, галеновые препараты, различные медицинские изделия.

Основными предприятиями в данной отрасли будут филиал АО «Химфарм», ТОО НПЦ «Рауан», ТОО «ЭкоФарм Интернейшнл», ТОО «КазМедПром», АО «Реактивные фосфорные соединения», ТОО «Кайнар», ТОО «СДТ Гроуп».

Кроме того, в агломерации имеется потенциал развития производства резиновых и пластмассовых изделий, таких как производство шин, резиновых покрытий для спортивных сооружений и др.

Можно отметить такие предприятия, как ТОО «СДТ Гроуп», ТОО «Вок Хаус», ТОО «Шымпласт», ТОО «Шымкент Профиль», ТОО «Шымкент пластик кубыр», ТОО «Семсер Лтд», ТОО «Дина-Н», ТОО «Бейне», ТОО «Каз Тел» и др. [5].

Существующие проблемы, сдерживающие развитие отраслей промышленности:

неконкурентоспособность большинства отраслей производства как на внешнем, так и на внутреннем рынке. Низкая производительность труда, высокие затраты на сырье, неразвитость транспортно-логистической инфраструктуры существенно повышают себестоимость производимой продукции;

использование устаревших технологий отдельными предприятиями, высокий моральный и физический износ оборудования и машин. Основные фонды промышленных предприятий характеризуются высокой изношенностью. Продолжают снижаться коэффициенты обновления и ликвидации основных фондов;

усложненные административные процедуры;

ограниченный доступ к передовым технологиям строительства и производства (как зарубежным, так и отечественным, вследствие их фактического отсутствия);

недостаток квалифицированных кадров (инженеры, проектировщики, технологи и т.Д.);

ограниченный доступ к финансированию для осуществления модернизации и диверсификации производства, в т.ч. для малого и среднего бизнеса.

Учитывая текущие проблемы в отрасли, необходимо принятие мер по наращиванию промышленного потенциала, таких как ввод в действие производств по выпуску продукции с новыми и улучшенными потребительскими свойствами для завоевания свободных рыночных ниш и сегментов рынка, улучшение качественной структуры предприятий за

Перспективы развития промышленности агломерации
Материалы Международной практической интернет-конференции «Актуальные Проблемы Науки» 
счет финансового оздоровления социально и экономически значимых для города организаций промышленности, сокращение и ликвидацию убыточности предприятий (включая государственные казенные), сохранение традиционных отраслей и производств, которые имеют положительную динамику темпов роста, содействие увеличению количества участников в индустриальных и промышленных зонах.

Реструктуризация промышленных предприятий агломерации позволит активизировать процесс модернизации промышленного производства и обеспечит устойчивое его развитие с учетом соблюдения экологических требований.

Проведение модернизации в отдельных отраслях промышленного комплекса необходимо осуществлять с учетом их специфики.

Основными задачами по повышению эффективного использования промышленного потенциала Шымкентской агломерации должны стать:

снижение налоговой нагрузки предприятий и принятие других мер государственного регулирования по активизации процесса инвестирования основного капитала промышленности;

ускорение процесса обновления основных производственных фондов на базе внедрения прогрессивного оборудования, машин и механизмов, в том числе и отечественного производства;

разработка и внедрение эффективных механизмов привлечения инвестиций в промышленность в целях увеличения собственных средств предприятий, банковских кредитов, иностранных инвестиций;

разработка и реализация инвестиционных проектов, ориентированных на создание и выпуск конкурентоспособной продукции;

концентрация ресурсов на приоритетных направлениях, прежде всего, экспортоориентированных и импортозамещающих производств.

Кроме общего развития отраслей экономики необходимо повышение конкурентоспособности на основе кластерного подхода, который получил широкое распространение в стратегиях развития большинства стран мира, в том числе в стратегиях развития агломераций. Кластеры признаны важным инструментом содействия промышленному развитию, конкурентоспособности и эффективности экономики.

С учетом специализации и наличием производственных мощностей агломерации наиболее перспективными в настоящее время являются следующие кластеры:

фармацевтический кластер (г. Шымкент);

нефтеперерабатывающий кластер (г. Шымкент);

строительный кластер (г. Шымкент, Тюлькубасский район);

текстильный кластер (г. Шымкент);

пищевые кластеры (мясной - Ордабасынский район, плодоовощной - Тюлькубасский район, по производству растительного масла - г. Шымкент);

металлургический кластер (г. Шымкент).

В настоящее время сдерживающим фактором и ключевыми проблемами развития кластеров в Казахстане являются отсутствие спроса и предложения на инновационную продукцию, неразвитость сервисной инфраструктуры, отсутствие критической массы инновационных и венчурных предпринимателей, способных конкурировать на внутренних и внешних рынках, несформированность системы трансферта, генерации и передачи знаний в экономику страны, низкий уровень проникновения открытых инноваций и их использование отечественным бизнесом, слабый научно-технический потенциал.

В результате, основной формой импорта технологий остается покупка технологического и производственного оборудования и комплектующих без приобретения

Перспективы развития промышленности агломерации
Материалы Международной практической интернет-конференции «Актуальные Проблемы Науки» 
инженерных решений, развития соответствующих компетенций, что свидетельствует о несовершенстве технологической политики страны.

Наиболее слабым звеном в кластерном развитии является острый дефицит бизнескомпетенций в частном секторе. Структура и потенциал предпринимательства, сконцентрированного в торгово-посреднической сфере и сфере неторгуемых услуг, требуют структурной модернизации отечественного бизнеса, формирования маркетинговых, технологических и инженерных компетенций у бизнеса, а также широкого и современного корпоративного сектора страны.

С учетом изложенного требуется концептуальная смена подходов и методов формирования и функционирования отечественных кластеров, основанных на активном развитии современных бизнес-компетенций и заимствовании новых технологий, с последующим переходом к реинжинирингу и генерации собственных знаний и технологий для развития новой технико-технологической платформы отраслей экономики.

Стимулирование развития возможных кластеров должны включать такие общесистемные меры как:

поддержка и развитие кооперации и сотрудничества участников;

развитие человеческих ресурсов;

развитие инноваций и технологий - развитие продуктовых, процессных инноваций и инноваций в области услуг;

создание бизнес-климата и инфраструктуры - улучшение условий для ведения бизнеса в рамках кластера.

Существенной мерой, призванной улучшить инвестиционный климат агломерации, способной привлечь инвестиции в реальный сектор экономики и содействовать модернизации экономики агломерации, станет создание и развитие специальных экономических и индустриальных зон как структуры, формирующей максимально комфортные условия для создания новых производств. При этом, данные зоны будут обладать готовой инфраструктурой, позволяющей потенциальным резидентам немедленно начать реализацию проектов.

Важнейшим элементом инновационной экономики Шымкентской агломерации в перспективе станет специальная экономическая зона «Оңтүстік» (далее - СЭЗ). Перспективная деятельность СЭЗ будет направлена на технологическое развитие хлопкоперерабатывающего производства, текстильной и швейной промышленности и привлечения производителей мировых торговых марок для производства текстильной продукции, высокотехнологичных производств, улучшения качества и расширения ассортимента производимой текстильной продукции.

В СЭЗ будут создаваться высокоэффективные, в том числе высокотехнологичные и конкурентоспособные производства, будет осуществляться освоение выпуска новых видов продукции, привлечение инвестиций.

На территории Шымкентской агломерации расположены пять действующих индустриальные зоны (две индустриальной зоны «Оңтүстік», «Тассай» в г. Шымкент и по одной в Байдибекском, Казыгуртском, Тюлькубасском районах - производство продуктов питания, переработка сельскохозяйственной продукции (овощей и фруктов) и производство строительных материалов, производство мебели. Одна индустриальная зона находятся на стадии строительства (индустриальная зона «Бадам» в Ордабасынском районе) [6].

Функционирование индустриальных зон позволит решить ряд задач:

вывод существующих производств из центра города;

привлечение инвестиционных ресурсов и трансферт передовых инновационных технологий;

Перспективы развития промышленности агломерации
Материалы Международной практической интернет-конференции «Актуальные Проблемы Науки» 
формирование системы подготовки и использования квалифицированных кадров в промышленном секторе.

Успешное развитие специальных экономических и индустриальных зон ускорит развитие национальной экономики путем создания условий для развития современных, конкурентоспособных производств, привлечения капитала, увеличения объема экспорта, роста доходов, повышения инновационной активности и повышения занятости населения страны.

В целом, устойчивый экономический рост промышленного комплекса Шымкентской агломерации будет базироваться на развитии высокотехнологичных, конкурентоспособных производств на основе активного проведения преобразований существующего научно-технического и производственного потенциалов.

Таким образом, Шымкентская агломерация станет центром развития экологически чистого и высокотехнологичного производства конкурентоспособной продукции агропромышленного комплекса, производства продукции легкой промышленности, горнодобывающей, фармацевтической, нефтеперерабатывающей промышленности.

\section{ЛИТЕРАТУРЫ}

1. Постановление Правительства Республики Казахстан от 22.02.2018 г. № 74 «Об утверждении Межрегиональной схемы территориального развития Шымкентской агломерации»;

2. Постановление Правительства Республики Казахстан от 30 декабря 2013 года № 1434 «Об утверждении Основных положений Генеральной схемы организации территории Республики Казахстан»;

3. Указ Президента Республики Казахстан от 1 августа 2014 года № 874 «Об утверждении Государственной программы индустриально-инновационного развития Республики Казахстан на 2015 - 2019 годы»;

4. Статистический сборник «Предварительные данные за 2017 год», Шымкент 2018;

5. Программа развития территории Южно-Казахстанской области на 2016-2020 годы;

6. Сайт управляющей компании «ONTUSTIK» http://iz-ontustik.kz

Перспективы развития промышленности агломерации
Материалы Международной практической интернет-конференции «Актуальные Проблемы Науки» 